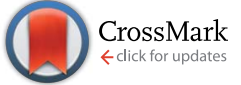

Cite this: J. Anal. At. Spectrom., 2016, 31, 1766

Received 31st March 2016 Accepted 4th July 2016

DOI: 10.1039/c6ja00121a

www.rsc.org/jaas

\section{Monolithic chromatography in speciation analysis of metal-containing biomolecules: a review}

\begin{abstract}
Radmila Milačič, ${ }^{\text {ab }}$ Tea Zuliani, ${ }^{a}$ Janja Vidmar ${ }^{\mathrm{ab}}$ and Janez Ščančar*ab
Monolithic supports are efficient stationary phases for most of the important chromatographic separation modes. They can be applied for the chromatographic separation of biomolecules, nanoparticles, proteins, peptides, nucleic acids and low molecular mass organic acids. At the industrial level, monolithic chromatography is frequently used for the purification of large plasmids and bacteriophages. Despite their high potential and simplicity of hyphenation to different mass spectrometric detectors, monoliths are rarely employed in elemental speciation analysis. The present overview extends over the applications of monolithic supports for chromatographic separation of a given chemical element species present in different biological samples where they were efficiently used as an alternative to commonly applied particle-packed chromatographic columns. The performances and applicability of monolithic supports in speciation analysis are discussed and the need for further investigations in this area emphasized.
\end{abstract}

\section{Introduction}

Metals play an essential role in living organisms. For understanding molecular mechanisms of metal-dependent life processes, it is necessary to study the interactions of metal ions and their species with genes, proteins, metabolites and other biomolecules within organisms and ecosystems. Hyphenated techniques that are used in speciation analysis typically combine a high resolution separation technique, like liquid or gas chromatography and gel or capillary electrophoresis, with selective and sensitive elemental (e.g. inductively coupled plasma mass spectrometry (ICP-MS)) or molecular mass spectrometric detectors (commonly with electrospray or matrixassisted laser desorption (MALDI) ionization). As a part of analytical methodology, they can importantly contribute to the information obtained from the experimental results thus extending the knowledge in the field of metallomics. ${ }^{1}$ The efficiency of separation significantly contributes to the overall integrity of such information. The common tool used for the separation of metal-biomolecule complexes is different chromatographic techniques. Among recent developments and emerging directions in chromatography, monolithic stationary phases acquired a major importance in high-performance liquid chromatography (HPLC). ${ }^{2,3}$ Monolithic chromatographic supports are made of a single piece of rigid porous material that is tightly sealed to the wall of a tube. They represent efficient stationary phases for most of the important chromatographic

${ }^{a}$ Department of Environmental Sciences, Jožef Stefan Institute, Jamova 39, SI-1000 Ljubljana, Slovenia. E-mail: janez.scancar@ijs.si; Fax: +3861 4773235; Tel: +3861 4773846

${ }^{b} J o z ̌ e f$ Stefan International Postgraduate School, Jamova 39, SI-1000 Ljubljana, Slovenia separation modes. The mobile phase flows through the pores of the separation medium at low back pressure, enabling the use of higher flow rates than those that are commonly applied in liquid chromatography. The resolution and capacity of monolithic chromatographic supports are independent of the flow rate. In general, the porosity of monolithic columns is much greater than that of particle packed columns. Convective mass transport enables fast and efficient chromatographic separation. Since monoliths represent a single body, they have no void volume. ${ }^{4}$ In a book edited by Švec, Tennikova and Deyl, a comprehensive review of the theoretical aspects of preparation, properties and separation using monolithic beds is provided, demonstrating also wide areas of their potential applications. ${ }^{5}$ Monoliths are formed mostly from inorganic silica, ${ }^{6}$ organic methacrylate based stationary phases ${ }^{4,7-9}$ and poly(styrene-co-divinylbenzene) materials. ${ }^{\mathbf{1 0}}$ The aspects of polymer chemistry relevant to the synthesis of monolithic materials and metathesis polymerization-derived monolithic supports have been outlined by Buchmeiser. ${ }^{\mathbf{1 0 1 1}}$ Monoliths are available in disk, column and tube packages. ${ }^{4}$ Nowadays, monolithic chromatography is widely used in industrial and preparative separation of biomolecules. ${ }^{7-9}$ Poly(styrene-codivinylbenzene)-based monolithic columns have been successfully applied in the field of proteomics for the rapid separation of peptides, proteins ${ }^{12}$ and ribonucleic acids, ${ }^{13}$ while the ringopening metathesis polymerization-derived monolithic anionexchangers were used for the analysis of double-stranded DNA fragments. ${ }^{14-16}$ Furthermore, a successful application of the ring-opening metathesis polymerization-derived monolithic supports for their intended use as precolumns in capillary liquid chromatography for on-line removal of protamineoligonucleotide nanoparticles was reported by Gatschelhofer 
et $a{ }^{17}{ }^{17}$ Methacrylate-based monolithic stationary phases also enable fast and efficient analyses of biomolecules and nanoparticles, ${ }^{18}$ they have been applied in purification of large plasmids and bacteriophages, ${ }^{\mathbf{1 9 , 2 0}}$ and offer chromatographic separation of proteins, ${ }^{21,22}$ peptides, ${ }^{23}$ nucleic acids ${ }^{4}$ and low molecular mass organic acids. ${ }^{24}$ Furthermore, methacrylate based monoliths are progressively used in the field of proteomics. $^{25-28}$

In spite of their high potential and simplicity in coupling to different detectors, monoliths were rarely used in elemental speciation analysis. ${ }^{29}$ The main drawback was related to the use of high salt content in eluents, which is not desirable when ICPMS is used as a detector. This also makes on-line combination of monolithic chromatography with electrospray ionization tandem mass spectrometry (ESI-MS-MS) difficult, resulting in the need for species structural characterisation. However, the recent advances in performances of ICP-MS instruments due to the development of the high matrix introduction (HMI) system allow direct analysis of samples with much higher levels of total dissolved solids than can be tolerated by conventional ICP-MS. Despite some disadvantages, there are several reports on the successful applications of monolithic chromatography in the determination of chemical species of elements. By the use of styrene-divinylbenzene co-polymer based monolithic stationary phases, chelating convective interaction media (CIM) monolithic disks were employed in a flow analysis system for the fractionation of labile copper $(\mathrm{Cu})$ species in environmental water samples. ${ }^{30}$ Complementary to particle packed columns, methacrylate-based CIM monolithic disks, bearing weak anionexchange diethylamine (DEAE) groups, were successfully applied in speciation analysis of zinc $(\mathrm{Zn})$ in environmental ${ }^{31}$ and chromium (Cr) in occupational health ${ }^{32}$ samples. Monoliths are also prospective separation tools that may be used for the rapid separation of metal-biomolecule complexes. Nevertheless, only a few research groups have investigated the possibility for their implementation in the field of metallomics. Pearson et $a .^{33}$ used reversed phase silica-based monolithic chromatography in the investigation of arsenic (As) urinary excretion after ingestion of rice. Five As species were determined in rice and in urine by using an ion-pairing monolithic silica column coupled to ICP-MS. Other applications were related to investigations of metal-biomolecule complexes in human serum by the use of methacrylate-based monoliths. ${ }^{34}$ In our group, as an alternative to the anion-exchange FPLC column, ${ }^{35}$ a CIM DEAE monolithic disk ${ }^{36}$ or column ${ }^{37}$ was used for the speciation of aluminium (Al) in human serum. The possibility of the effective cleaning of the chromatographic supports with $\mathrm{NaOH}$ that appreciably reduced the column blanks ${ }^{37}$ and the opportunity of coupling a large volume CIM column $(8 \mathrm{~mL})$ to the sensitive ICP-MS detector enabled the separation and quantification of $\mathrm{Al}$ bound to transferrin in human serum at physiological concentration levels. ${ }^{37}$ Another successful application was the use of a $1 \mathrm{~mL}$ CIM DEAE-1 column in the study of the distribution of cisplatin in human serum. ${ }^{38}$ In this work the performances of monolithic chromatography were compared to those of particle packed FPLC columns. The CIM monolithic column was found to be more robust and enabled analyses of more than 150 serum samples without cleaning of the column support. By the use of CIM DEAE disks, Hann et al. ${ }^{39}$ developed a high throughput screening assay intended for mapping the metallodrugbiomolecule interaction. In the fully automated on-line $2 \mathrm{D}$ system combined with ICP-MS detection, sequential switching of the eluent from the SEC column to two parallel CIM disks enabled direct fractionation and speciation analysis of cisplatin in human serum. Hasegawa et al. ${ }^{\mathbf{4 0}}$ reported trace metal speciation in human serum based on the separation of human serum proteins by monolithic chromatography and trace metal mapping analysis. A CIM DEAE disk was employed for the separation of proteins, which was followed on-line by using a detection system that consisted of a UV absorption detector and ICP-MS. For the identification of the separated proteins, successive chromatographic fractions were collected and subjected to MALDI-TOF-MS analysis. The concept of monolithic chromatography was recently extended also to the use of an anion-exchange polymeric micro-monolithic column coupled with ICP-MS in the investigation of trace element speciation in human serum. ${ }^{\mathbf{4 1}}$ Applying the proposed method, speciesspecific differences between commercially available Seronorm L1 and L2 trace element reference materials were identified. Speciation analysis of heparinized plasma, EDTA plasma and serum from healthy volunteers revealed that EDTA strongly affects speciation of $\mathrm{Fe}$ and $\mathrm{Zn}$, while the effect of lithiumheparin on the speciation of metals in human plasma was negligible. Another successful application of monolithic chromatography was the use of a CIM DEAE-1 monolithic column in speciation of Zn-citrate in human milk. ${ }^{\mathbf{4 2}}$ Quantitative separation of Zn-citrate complexes $\left([\mathrm{Zn}(\mathrm{Cit})]^{-}\right.$and $\left[\mathrm{Zn}(\mathrm{Cit})_{2}\right]^{4-}$ ) was carried out and the separated $\mathrm{Zn}$ species were determined "offline" by flame atomic absorption spectrometry (FAAS) or "online" by ICP-MS. In fractions collected under the chromatographic peaks, the Zn-binding ligand was identified by ESI-MSMS. The results demonstrated that about $23 \%$ of the total $\mathrm{Zn}$ was present in the low molecular mass (LMM) milk fraction and that LMM-Zn corresponded to Zn-citrate. A CIM DEAE-1 monolithic column was also applied in the speciation of LMMNi complexes in tea infusions. ${ }^{43}$ The column was hyphenated to ICP-MS and the ligands eluted in fractions which contained $\mathrm{Ni}$ identified "off-line" by hybrid quadrupole-time of flight mass spectrometry (Q-TOF MS). In white, green, oolong and black tea (Camellia sinensis) and flowers of herbal chamomile (Matricaria chamomilla) infusions, Ni was found to be present in the chromatographic fraction in which quinic acid was identified by QTOF, while in the hibiscus (Hibiscus sabdariffa) tea infusion, the results of speciation analysis showed that $\mathrm{Ni}$ is present in its divalent ionic form. An innovative approach of the use of monolithic chromatography was the application of conjoint liquid chromatography (CLC) for simultaneous two-dimensional separation of ionic forms of metal-based chemotherapeutics from the portions bound to serum proteins. ${ }^{\mathbf{4 4 , 4 5}}$ The method is based on assembling CIM Protein G and CIM DEAE disks in a single housing forming a CLC monolithic column. On the first disk the chemotherapeutic bound to immunoglobulin $\mathrm{G}$ is separated, while on the second disk the unbound form of 
the chemotherapeutic is separated from the portion bound to albumin and transferrin. In combination with UV and ICP-MS detection the kinetics of binding of Pt and Ru-based chemotherapeutics to serum proteins were investigated in spiked human serum..$^{44,45}$

The purpose of this review is to give an overview of recent successful applications of monolithic chromatography used for the separation of metal binding biomolecules in speciation analysis. The performances and advantages of monolithic supports are evaluated and the potential of their further use as a complementary tool to particle packed HPLC columns in the separation of metal-biomolecule complexes in different biological samples is estimated.

\section{Monolithic chromatography as a promising tool for the separation of metal-biomolecule complexes}

Speciation analysis requires efficient and rapid separation of element species and their highly sensitive detection. In order to preserve the original species present in the sample and prevent any species conversion during analysis, fast separation is usually required. Monolithic chromatographic supports in general offer faster separation than traditional particle packed columns. So, recently monolithic chromatography is being gradually introduced, as a promising tool, for the separation of metal-biomolecule complexes. Stationary phases based on porous monolithic silica ${ }^{33}$ or methacrylate-based monolithic supports $^{36-41}$ have been successfully applied in the field of metallomics. These applications and characteristics of monolithic stationary phases are summarised in Table 1 . The potential of the use of monolithic chromatography for the separation of metal-biomolecule complexes is evaluated in the following sections.

\subsection{Silica-based monolithic supports for arsenic speciation}

HPLC chromatography using a polymeric anion-exchange column Hamilton PRP X 100 was most frequently applied for the speciation of As(III), As(v), monomethylarsonate (MMA) and dimethylarsinate (DMA). ${ }^{46}$ The separation of these As species was completed within 15 to $20 \mathrm{~min}$. Silica based monolithic columns, in particular those modified for reversed-phase separations, have also appropriate characteristics for the speciation of As. Pearson et $a .^{33}$ investigated the potential of the use of ion-pair liquid chromatography for rapid separation of As species. For this purpose, they coupled a Chromolith reversed-phase monolithic silica column to ICP-MS. Tetrabutyl ammonium bromide (TBAB) was used as an ion-pairing reagent. In order to achieve selective and sensitive separation of As species, the composition and $\mathrm{pH}$ of the mobile phase were optimised $\left(10 \mathrm{mM} \mathrm{L}^{-1}\right.$ phosphate buffer containing $1.0 \%(\mathrm{v} / \mathrm{v})$ methanol, pH 5.6). As presented in Fig. 1, under the optimal chromatographic conditions, fast and efficient separation of As(III), arsenobetaine (AsB), DMA, MMA and As(v) was obtained within $3 \mathrm{~min}$. The procedure developed was applied to the speciation analysis of As in urine and food samples in an ingestion experiment designed to investigate the effect of rice consumption on As exposure in humans. Data of the urinary As excretion revealed that American long rice significantly increases the excretion of DMA in human urine. In this work, the main advantage of monolithic chromatography over the use of conventional particle packed columns was the great reduction in the separation time.

\subsection{Methacrylate-based monolithic supports for elemental speciation in biological samples}

Methacrylate-based monoliths bearing ion-exchange functional groups are commercially available in disk, column and tube packages $^{4}$ and specially designed also as micro-columns. They possess excellent mechanical and chemical stability over a wide $\mathrm{pH}$ range and withstand the regeneration with $\mathrm{NaOH}^{47}$ Disks are the smallest monolithic columns. They are designed so that they fit into a housing specially made for them. Up to four disks may be stacked together into a single CIM housing increasing the capacity of such monolithic supports, while its resolution remains unchanged. It is also possible to prepare a CIM conjoint monolithic column (CLC) by placing CIM disks with different active groups into a single housing. ${ }^{44,45}$ In addition to small disks, larger CIM monolithic columns are also available as ready-to-use. Of different possible applications, separation of proteins still prevails among ion-exchange methacrylate-based monoliths. ${ }^{4}$ In terms of separation power and capacity, CIM monolithic supports are advantageous over conventional chromatographic columns packed with particles. Their usage allows eluents to be applied during separation at high flow rates without any increase of back pressure, hence enabling fast separation and rapid regeneration of supports. They exhibit low nonspecific binding of biomolecules, resulting in excellent recoveries. CIM monolithic supports are also easy to handle, can be coupled to various detectors, and offer great potential for the separation of charged biomolecules. The additional benefits are their robustness, long lifetime and relatively low cost.

\subsection{Speciation of $\mathrm{Al}$ in human serum}

The chemical speciation of $\mathrm{Al}$ in human serum is of crucial importance in assessing individual compounds that may contribute to Al neurotoxicity. Physiological concentrations of Al in human serum are very low, around $2 \mathrm{ng} \mathrm{mL}{ }^{-1}$. The complexity of the serum constituents, the low total concentration of $\mathrm{Al}$, the high risk of contamination and the tendency of $\mathrm{Al}$ to be adsorbed by different chromatographic supports make speciation of $\mathrm{Al}$ in human serum a difficult task for analytical chemists. To obtain reliable analytical data in $\mathrm{Al}$ speciation, it is of extreme importance to prevent all possible sources of contamination. By the use of high density polyethylene or Teflon laboratory ware and appropriate cleaning procedures to remove traces of $\mathrm{Al}$ from eluents, reagents, columns and filtering devices, speciation analyses were possible in spiked serum samples or in the serum of patients with elevated concentrations of $\mathrm{Al}^{48}{ }^{4}$ For characterization and quantification of the Al-binding proteins in human serum, analytical procedures combining size-exclusion chromatography (SEC), anionexchange chromatography, UV and element specific detectors 


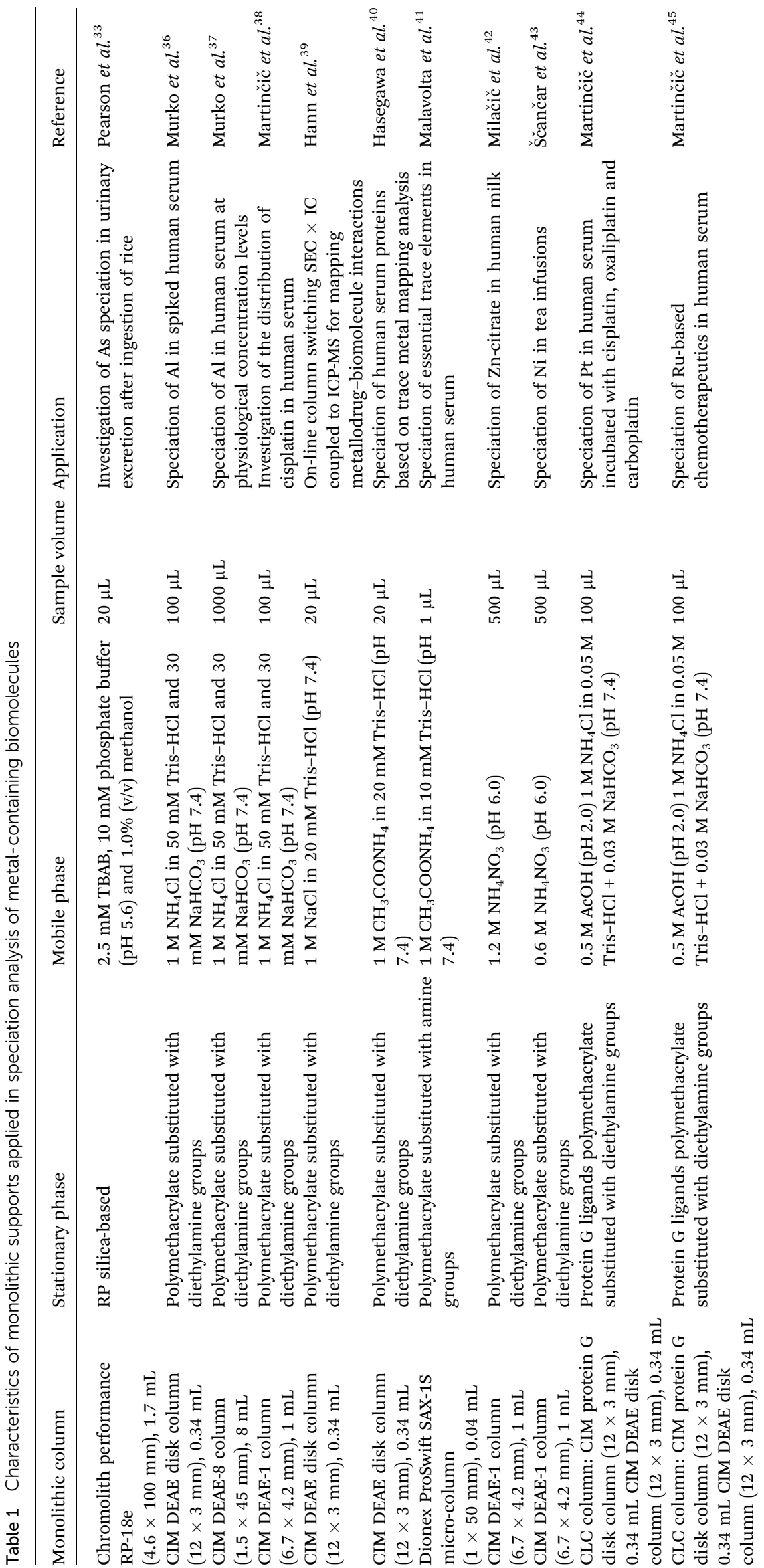




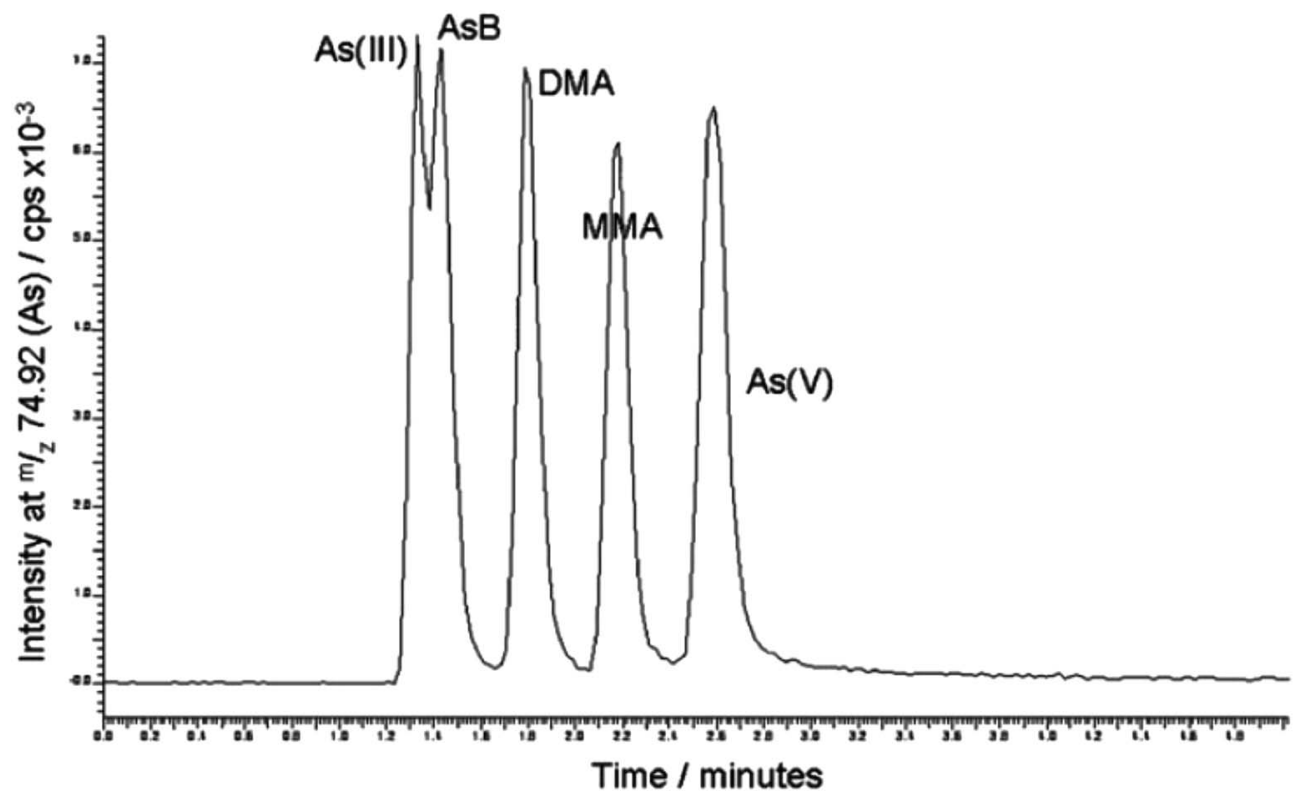

Fig. 1 Optimised separation of 5 arsenic species contained in $50 \mu \mathrm{g} \mathrm{L}^{-1}$ mixed standard solution (reproduced from ref. 33 with permission from The Royal Society of Chemistry).
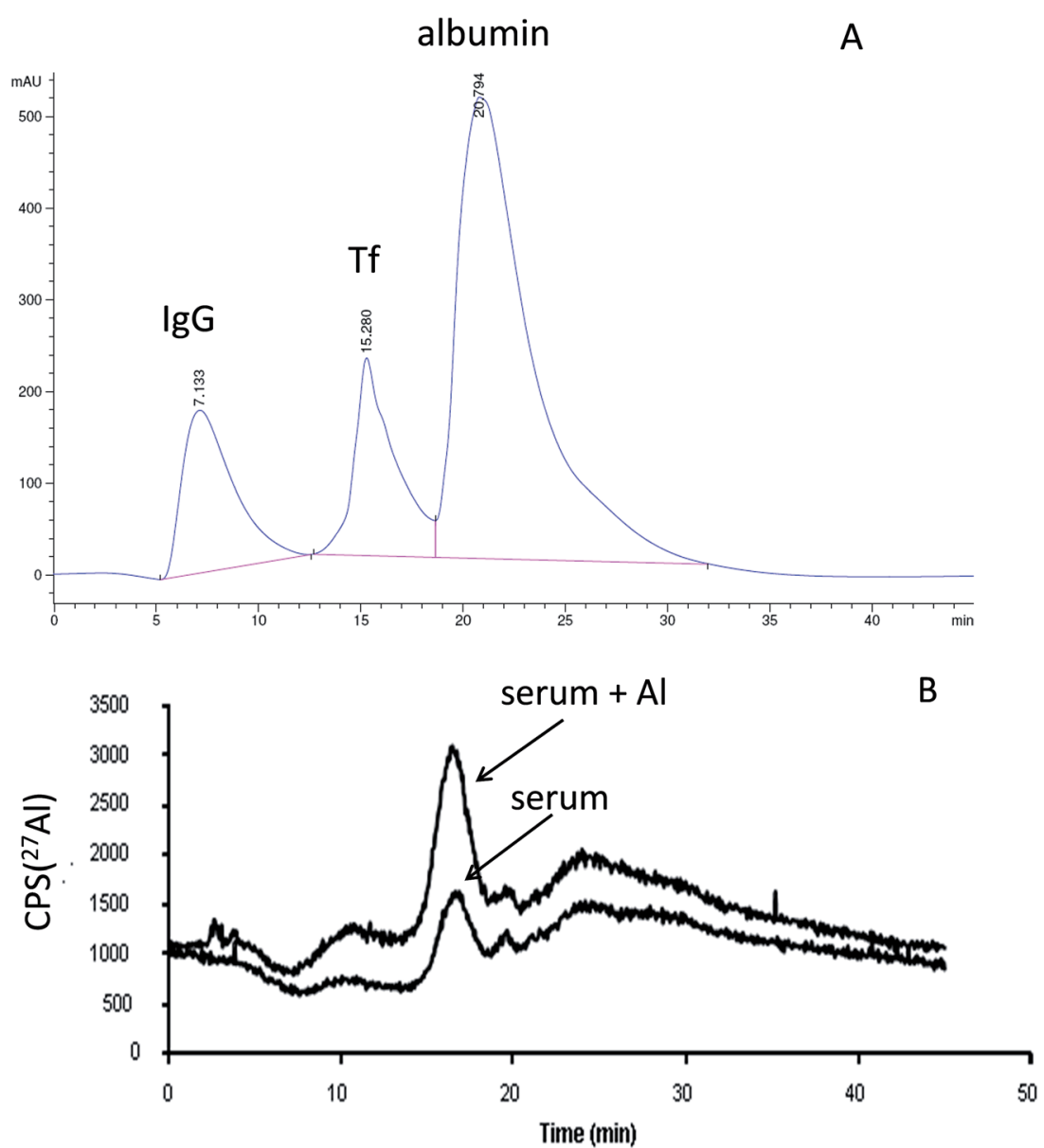

Fig. 2 (A) Separation of standard serum proteins by using an anion-exchange CIM DEAE column using UV (278 nm) and ICP-MS detection. (B) The Al elution profiles for the speciation of Al in unspiked $(1+4)$ and spiked serum samples $\left(1+4\right.$, spike in the diluted sample $\left.2 \mathrm{ng} \mathrm{mL} \mathrm{m}^{-1} \mathrm{Al}\right) \mathrm{when}$ CIM DEAE-ICP-MS was applied after pre-separation of LMM-Al species by SEC (reproduced from ref. 37 with permission from the American Chemical Society). 
were usually applied, while identification of the Al binding ligand was performed by SDS-PAGE. ${ }^{48}$ An anion-exchange FPLC Mono Q column was used by several researchers for the separation of $\mathrm{Al}$ species of the high molecular mass (HMM) serum fraction. ${ }^{35,49}$ The results of these studies revealed that about $90 \%$ of $\mathrm{Al}$ in human serum was bound to $\mathrm{Tf}$.

Since there are no reference materials for speciation analysis of $\mathrm{Al}$, the use of complementary analytical procedures is essential. As an alternative to ion-exchange FPLC columns, ionexchange CIM monolithic supports were complementarily applied. ${ }^{36,37}$ Initial investigations indicated that the weak anionexchange CIM DEAE disk exhibits all the potential needed for its successful application. To prevent co-elution of low molecular mass (LMM) Al species with HMM-Al compounds on the CIM disk, serum proteins were first separated from LMM-Al fraction by the use of SEC. A protein peak was collected $(5.0 \mathrm{~mL})$ and 0.1 $\mathrm{mL}$ of the sample aliquot injected onto the disk that was coupled on-line to UV and ICP-MS detection systems. As an eluent $1 \mathrm{M} \mathrm{NH}_{4} \mathrm{Cl}$ in $50 \mathrm{mM}$ Tris- $\mathrm{HCl}$ and $30 \mathrm{mM} \mathrm{NaHCO}$ buffer ( $\mathrm{pH}$ 7.4) was used in gradient elution. Selective separation of IgG, Tf and albumin is obtained in $10 \mathrm{~min}$. Al was separated at elution time characteristic of the Tf peak. The time of separation of serum proteins on the CIM disk (10 min) is shorter in comparison to that on the FPLC column (15 min). ${ }^{35,49}$ The results demonstrated that the percentage of $\mathrm{Al}$ bound to $\mathrm{Tf}$ was $90 \pm 3 \%$. These data are in agreement with our previous observations $^{35}$ and observations of other researchers ${ }^{49}$ who applied a particle packed Mono Q FPLC column in the speciation of Al. The developed CIM DEAE-ICP-MS speciation procedure enabled reliable determination of the concentration and composition of $\mathrm{Al}$ bound to proteins when the concentration of

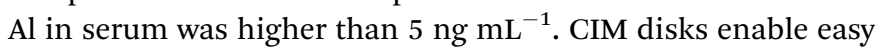
manipulation during the cleaning procedure as well as simple coupling to ICP-MS. In order to lower the limits of detection that would enable the speciation of $\mathrm{Al}$ at physiological concentration levels in human serum, Murko et $a l .{ }^{37}$ applied the same chromatographic monolithic support and eluents using a larger 8 mL CIM DEAE-8 column. A larger column, with higher capacity enabled injection of a greater sample volume $(1 \mathrm{~mL})$. However, the limiting factor to achieve lower limits of detection was the extraneous contamination with Al. The ability of the CIM DEAE8 column to sustain rigorous cleaning of the chromatographic support with $\mathrm{NaOH}$ and efficient cleaning of eluents used in the chromatographic procedure resulted in extremely low blanks (below $0.15 \mathrm{ng} \mathrm{Al} \mathrm{mL}{ }^{-1}$ ). By coupling the CIM DEAE-8 column to ICP-MS, speciation of $\mathrm{Al}$ was possible in human serum at normal physiological concentration levels from 0.5 to $2 \mathrm{ng} \mathrm{Al}$ $\mathrm{mL}^{-1}$. A UV chromatogram for the separation of serum proteins and an overlay of Al elution profiles of unspiked and spiked human serum after pre-separation of the LMM-Al species by SEC are presented in Fig. 2. Data demonstrated that about 90\% of $\mathrm{Al}$ in unspiked and spiked human serum was separated at the retention volume characteristic of Tf. The Al-binding ligand was further identified by Acquity ultra performance liquid chromatography-electrospray ionization mass spectrometry (UPLC-ESIMS). The results again confirmed that the Al-binding serum protein is Tf. The data on the speciation of $\mathrm{Al}$ in serum at physiological concentration levels represent an important basis for studies of the Al distribution and its fate in the human body. CIM monolithic stationary phases can be recommended as a favourable separation support over particle packed FPLC columns for the speciation of Al-binding proteins in human serum. Due to its high capacity and the possibility of the effective cleaning that significantly reduced the column blanks, the CIM DEAE-8 column enabled quantitative speciation analysis of $\mathrm{Al}$ at physiological concentration levels.

\subsection{Speciation of essential trace elements in human serum}

Speciation analysis of essential trace elements in human serum provides important information on the nutritional status of the body, and homeostatic mechanisms that regulate their transport processes, acute phase reactions, and protection against oxidative damage. Malavolta et al. ${ }^{\mathbf{4 1}}$ developed a fast method for the simultaneous speciation of iron (Fe), copper $(\mathrm{Cu})$, zinc $(\mathrm{Zn})$ and selenium (Se) in human serum by the use of monolithic anion-exchange micro-columns installed on a tandem HPLC system coupled on-line with an ICP-MS detector. The system used for the separation of serum proteins was set in tandem LC mode with off-line column regeneration. Two ProSwift SAX-1S polymethacrylate-based monolithic micro-columns $(0.04 \mathrm{~mL})$ with amine functional groups were switched through the flow manager valve back and forth between the analysis and the regeneration flow paths, thereby allowing off-line column regeneration and equilibration. While one column was equilibrated, the system injected the next sample onto the other column, shortening the time of analysis. As an eluent $1 \mathrm{M}$ ammonium acetate in $10 \mathrm{mM}$ Tris buffer ( $\mathrm{pH}$ 7.4) was used in gradient elution. A representative example of chromatographic separation of $\mathrm{Fe}, \mathrm{Cu}, \mathrm{Zn}$ and Se species in human serum using a monolithic anion-exchange micro-column with ICP-MS detection is presented in Fig. 3. From this figure, it is evident that elements are eluted at different elution times. Based on overlapping of elution profiles with standard human serum proteins, specific binding of elements was estimated, while quantification of individual element species was performed by peak area normalization and/or absolute quantification by calibration curves. Authors stated that despite three to six times faster analysis time in comparison to commonly applied chromatographic procedures, the resolution of separated element species was not compromised. The procedure developed was applied in speciation analysis of human plasma after addition of different anticoagulant agents e.g. lithium-heparin or EDTA. As expected, EDTA strongly affected speciation, while almost no changes in speciation of $\mathrm{Fe}$ and $\mathrm{Zn}$ were seen in heparinised plasma. In their work authors observed also species specific differences in speciation analysis of Seronorm L1 and Seronorm L2 commercially available trace element reference materials. Despite the very small amount of sample injected $(1 \mu \mathrm{L})$ the reproducibility was acceptable for the most species investigated. The developed tandem micro-column chromatographic separation could represent a tool for fast screening of deviations in the trace element distribution in human serum initiated by various diseases or age-related changes. 

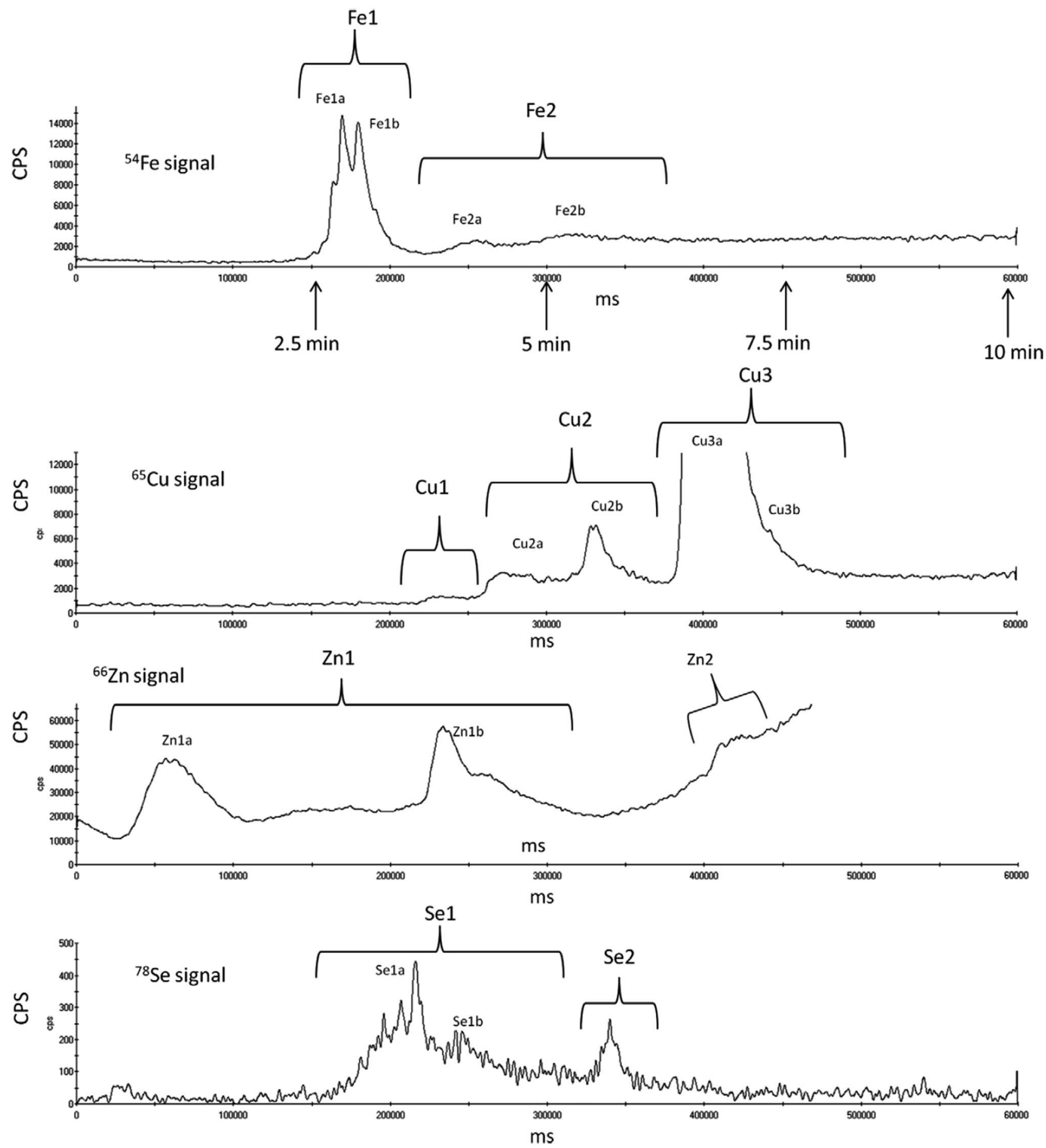

Fig. 3 Chromatographic separation of $\mathrm{Fe}, \mathrm{Cu}, \mathrm{Zn}$, and Se species obtained by SAX-ICP-MS in normal human serum. Signals are reported as counts per second (CPS) for ${ }^{54} \mathrm{Fe},{ }^{65} \mathrm{Cu},{ }^{66} \mathrm{Zn}$, and ${ }^{78} \mathrm{Se}$. The $x$ axis reports milliseconds (ms) as originally displayed in the ICP-MS software. The respective time in minutes $(\mathrm{min})$ is highlighted by the arrows below the chromatogram of the ${ }^{54} \mathrm{Fe}$ signal (reproduced from ref. 41 with permission from Elsevier).

\subsection{Speciation of $\mathrm{Zn}$-citrate in human milk}

In human milk, zinc ( $\mathrm{Zn})$ is fractionated between high molecular mass fraction containing milk proteins and low molecular mass fraction where citrate was predicted to be the most important ligand for its complexation. It was demonstrated in numerous investigations that the bioavailability of $\mathrm{Zn}$ for infants is much higher in human than in any other type of animal milk consumed by humans. In order to quantitatively determine highly bioavailable Zn-citrate in human milk, authors applied speciation analysis, which consists of CIM 
DEAE monolithic chromatography, flame atomic absorption spectrometry (FAAS) or inductively coupled plasma mass spectrometry (ICP-MS) and hybrid quadruple time of flight mass spectrometry (Q-Tof Premier). ${ }^{42}$ Speciation analysis of $\mathrm{Zn}$ in biological samples was a challenging task because at physiological $\mathrm{pH}$ values $\mathrm{Zn}$ is readily adsorbed on different chromatographic columns, interacts with numerous buffer solutions, and many of its complexes, including Zn-citrate, are moderately stable and hence, can be easily partially broken during separation. Method development started with the optimisation of instrumental parameters of chromatographic separation and spectrometric detection using synthetic solutions of Zn-citrate that was prepared in HEPES, MOPS or MES buffers, which do not interact with $\mathrm{Zn}$. To separate $\mathrm{Zn}$ species $0.5 \mathrm{~mL}$ of the sample was injected onto a CIM DEAE- 1 monolithic column and an aqueous - $1.2 \mathrm{~mol} \mathrm{~L}^{-1} \mathrm{NH}_{4} \mathrm{NO}_{3}$ linear gradient elution applied for $10 \mathrm{~min}$ at a flow rate of $1.0 \mathrm{~mL}$. After chromatographic separation, the concentration of $\mathrm{Zn}$ was determined either off-line in the collected fraction by flame atomic absorption spectrometry (FAAS) or on-line by inductively coupled plasma mass spectrometry (ICP-MS). The Zn-binding ligand was identified on the basis of the retention time and also by electrospray ionization tandem mass spectrometry (ESI-MSMS). The analytical procedure developed enables reliable and quantitative speciation of $\mathrm{Zn}$-citrate within the $\mathrm{pH}$ interval from 5 to 7 , where $[\mathrm{Zn}(\mathrm{Cit})]^{-}$and $\left[\mathrm{Zn}(\mathrm{Cit})_{2}\right]^{4-}$ complexes coexist, with the limit of detection 0.01 and $0.0005 \mu \mathrm{g} \mathrm{mL}{ }^{-1}$ of Zn-citrate
(FAAS and ICP-MS, respectively). It was successfully applied in $\mathrm{Zn}$ speciation in human milk. The results revealed that in the LMM milk fraction $\mathrm{Zn}$ is bound exclusively to citrate.

\subsection{Speciation of $\mathrm{Ni}$ in tea infusions}

In this application of monolithic chromatography, complete speciation analysis, comprising the separation on a weak anion exchange DEAE-1 monolithic column, the detection by ICP-MS and the ligand identification by Q-TOF MS, was implemented with the aim to study the Ni speciation in tea infusions of black, green, white, red (dried leaves of Camellia sinensis), chamomile and hibiscus tea (dried flowers of Matricaria chamomilla and Hibiscus sabdariffa, respectively).$^{43}$

$\mathrm{Ni}$ is a non-essential trace element, which if present in an average daily diet is considered as safe for healthy individuals. It's necessary only for individuals who already suffer from contact allergy to $\mathrm{Ni}$ and may develop systemic reactions from its dietary ingestion to keep dietary exposure to $\mathrm{Ni}$ under control. Prevailing sources of Ni in the human population are drinking water and different beverages with relatively high levels of Ni. Among such beverages are also various types of tea infusions.

In the study described, ${ }^{43}$ samples of various dried tea leaves or flowers with a median total concentration of $5.4 \mathrm{mg} \mathrm{Ni} \mathrm{kg} \mathrm{kg}^{-1}$ were analysed. Up to $85 \%$ of the total $\mathrm{Ni}$ was extracted with water during tea infusion preparation. Ni speciation analysis of tea infusion samples was carried out under the optimised

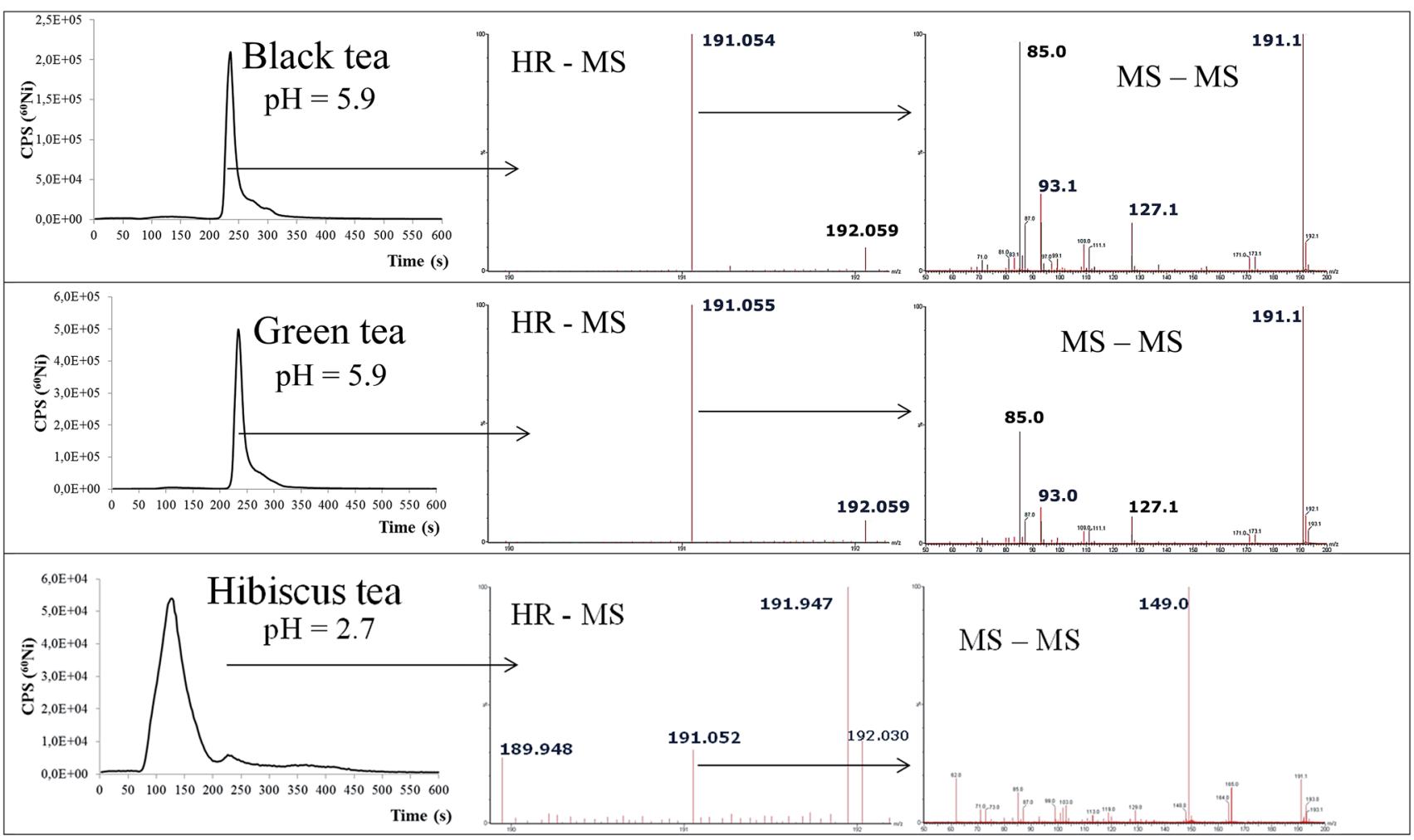

Fig. 4 Speciation of Ni in black, green and hibiscus tea infusions by the CIM DEAE-1 - ICP-MS procedure (left column) and HR MS spectra (middle column) and MS-MS spectra (right column) of the Ni species eluted under the chromatographic peaks (adopted from ref. 43 with permission from Springer). 
chromatographic conditions. Separation of Ni species on the 1 $\mathrm{mL}$ weak anion-exchange monolithic column was completed in 10 min by applying aqueous $0.6 \mathrm{~mol} \mathrm{~L} \mathrm{~L}^{-1} \mathrm{NH}_{4} \mathrm{NO}_{3}$ linear gradient elution with column recoveries close to $100 \%$. Recoveries were lower when a strong ion-exchange support with quaternary amino groups was tested for the same purpose as it breaks the moderately stable Ni species present in tea infusions. Separation of Ni species was followed by ICP-MS monitoring $\mathrm{m} / \mathrm{z}$ 60 and ligand identification by Q-TOF MS operating in high resolution and MS-MS modes. Data on Ni speciation in the samples analysed are presented in Fig. 4.

The main finding of this study was that with the exception of hibiscus tea, in all analysed samples of tea infusions, Ni was found to be mainly associated with quinic acid and not, as reported in the literature cited, with relatively high molecular mass polyphenols. Quinic acid was identified as the low molecular mass organic ligand with which $\mathrm{Ni}$ is complexed in all the tea infusions of slightly acidic $\mathrm{pH}(5.8 \pm 0.2)$. In the hibiscus tea infusion, which had a $\mathrm{pH}$ of 2.7 , $\mathrm{Ni}$ was found to be present in ionic divalent form, suggesting that its speciation in tea infusions is $\mathrm{pH}$ dependent. Authors concluded also that the speciation method developed is yet another example of the successful application of monolithic chromatography in speciation analysis and that new data on Ni speciation in tea infusions can be important in understanding its bioavailability, possible influence on the quality of tea and perhaps also metabolic processes in plants, where quinic acid is an important natural metabolite.

\subsection{Investigations of metallodrug-biomolecule interactions in human serum}

CIM monolithic chromatography was implemented also for studying the interaction of metallodrugs with proteins in biological samples, which play a key role in the preclinical and clinical drug development.
Hann et al..$^{39}$ developed a two-dimensional fully automated system in which the intact proteins were separated in the first dimension by SEC that was followed on-line by ion exchange chromatography (IC) employing two parallel CIM DEAE disks. Since covalent and non-covalent interactions are essential in this context, a native orthogonal separation was a prerequisite. The cycle time of separation using gradient elution with $1 \mathrm{M}$ $\mathrm{NaCl}$ in $20 \mathrm{mM}$ Tris-HCl (pH 7.4) and applying on-line ICP-MS detection was $3 \mathrm{~min}$. While the first disk was being eluted within $3 \mathrm{~min}$, the other was being loaded from the SEC column. Sequential switching of the eluent from the SEC column to two parallel CIM disks enabled direct fractionation and speciation analysis of cisplatin in human serum. The elution profile of the protein was monitored by ICP-MS as $\mathrm{SO}^{+}$polyatomic species via the dynamic reaction cell technique. Separation of albumin and Tf cisplatin adducts on the CIM disk is presented in Fig. 5. The developed throughput screening assay for metallomics exhibits increased selectivity compared to one-dimensional LC-ICP-MS. By injecting only $20 \mu \mathrm{L}$ of the sample, quantitative determination of anionic species with absolute limits of detection in a low pM range (regarding sulphur) is possible. An important advantage of the SEC $\times$ IC setting in combination with ICP-MS elemental detection is the potential for mapping any candidate metallodrug interactions with proteins in biological samples.

Martinčič et al. ${ }^{38}$ applied a CIM DEAE-1 $(1 \mathrm{~mL})$ monolithic column with higher capacity than the CIM disk in investigations of the distribution of cisplatin in human serum. First, rapid Pt fractionation was performed by SEC on a Hi-trap desalting column. A $0.1 \mathrm{~mL}$ aliquot of the protein fraction was then injected onto a CIM DEAE-1 column. By applying gradient elution with $1 \mathrm{M} \mathrm{NH}_{4} \mathrm{Cl}$ in $50 \mathrm{mM}$ Tris- $\mathrm{HCl}$ and $30 \mathrm{mM} \mathrm{NaHCO}_{3}$ (pH 7.4) and coupling the column on-line to UV and ICP-MS, interactions of cisplatin with albumin, Tf and IgG, or their mixture were studied. The protein peak was collected after preseparation by SEC, or the sample was injected directly onto a CIM DEAE-1 column (Fig. 6). The results of fractionation

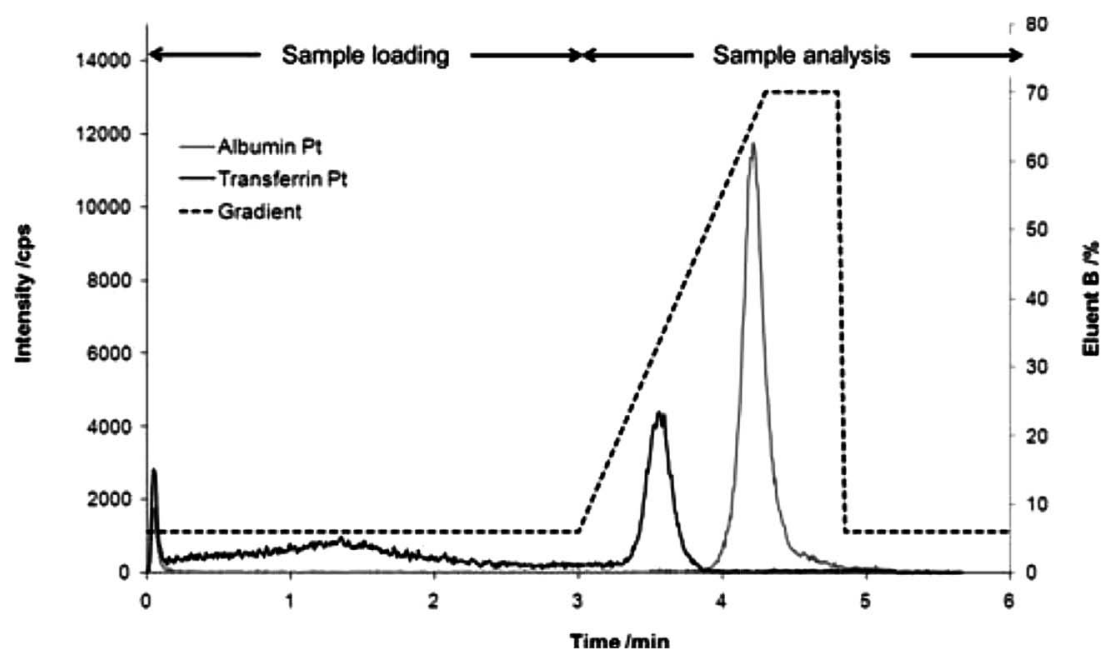

Fig. $5 \mathrm{CIM}$ disk separation of albumin and transferrin cisplatin adducts simulating the sample loading phase and the analysis period of 3 min each. The Pt concentration was $160 \mathrm{ng} \mathrm{g}^{-1}$ and $35 \mathrm{ng} \mathrm{g}^{-1}$ for the albumin and the transferrin adduct respectively (reproduced from ref. 39 with permission from The Royal Society of Chemistry). 
revealed that more than $80 \%$ of $\mathrm{Pt}$ in serum was eluted with proteins and the remaining portion as unbound cisplatin. Cisplatin did not interact with IgG. It exhibited a small interaction with Tf, and was strongly bound to albumin. Experimental data proved that the fraction eluted under the IgG peak corresponds to unbound cisplatin, enabling direct speciation analysis of cisplatin in the serum of cancer patients who received cisplatin-based chemotherapy. In parallel to monolithic chromatography, Pt speciation was also performed by using a Mono Q FPLC particle packed column coupled to ICPMS. Two complementary speciation procedures gave statistically comparable results. Good repeatability (RSD below 3\%) of consecutive chromatographic separations of the spiked serum sample was obtained for both Pt speciation procedures. The limit of detection (LOD) for separated Pt species by applying conventional and monolithic chromatography was found to be $0.06 \mathrm{ng}$ Pt $\mathrm{mL}^{-1}$. The low LOD enabled speciation of Pt in the serum of cancer patients treated with cisplatin. In comparison to the CIM monolithic column, the particle packed FPLC column exhibited better resolving power. However, the CIM DEAE-1 column is an appropriate separation support for its intended use in speciation of $\mathrm{Pt}$ and possibly other metallodrugs in human serum. It was found to be more robust and enabled analyses of much larger series of serum samples. Due to its ability for regeneration and equilibration at high flow rates $\left(10 \mathrm{~mL} \mathrm{~min}^{-1}\right)$, efficient removal of retained serum constituents from the column support is possible, which contributed to extremely repeatable and reproducible separations. At least 150 successive serum separations could be performed before the regular cleaning of the column was necessary. This is a great advantage over the use of conventional particle packed FPLC columns.

Further important improvement of the analytical method for the speciation of $\mathrm{Pt}$ in human serum originating from anticancer drugs (cisplatin, oxaliplatin and carboplatin) was made by the same group by the introduction of conjoint liquid chromatography (CLC). ${ }^{44}$ Two monolithic convective interaction media (CIM) disks namely, CIM protein G and CIM DEAE, were assembled together in a single housing forming a CLC monolithic column. This column was coupled on-line to UV and ICPMS detectors. Such a set-up allows rapid two-dimensional separation by affinity and ion-exchange (IE) modes to be carried out in a single chromatographic run. Before two-dimensional chromatographic separation of Pt-species was carried out chromatographic conditions were optimised separately for the CIM protein $\mathrm{G}$ and DEAE disks. A CIM protein G disk was
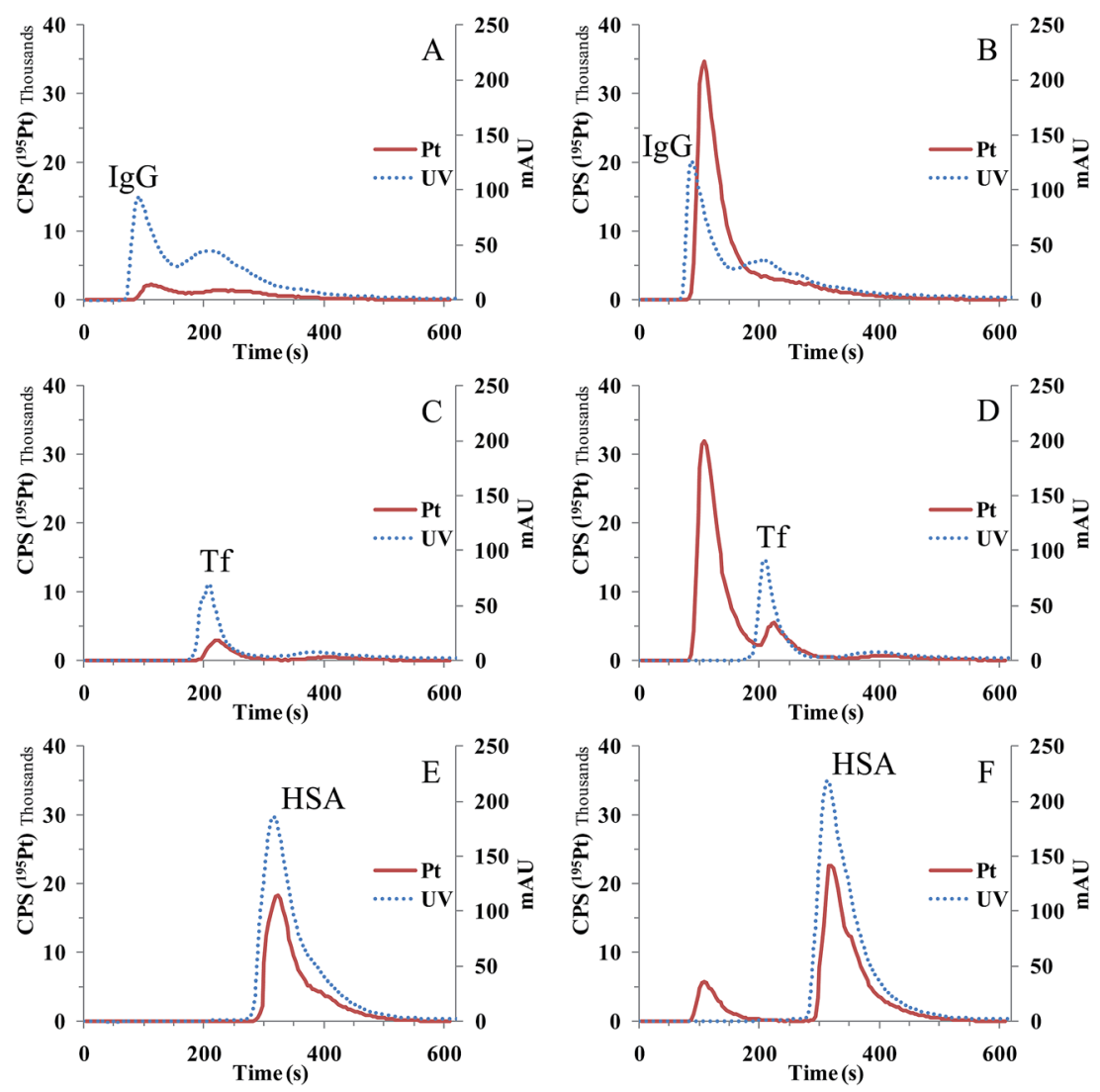

Fig. 6 Separation of standard serum proteins IgG (A and B), Tf (C and D) and HSA (E and F) spiked with CDDP (200 ng Pt mL ${ }^{-1}$ ) on a CIM DEAE-1 column. The protein peak was collected after pre-separation by SEC (,$C$ and $E$ ) or sample injected directly onto the CIM DEAE-1 column (B, D and F). $0.1 \mathrm{~mL}$ of the 5 times diluted sample was injected onto the CIM DEAE-1 column, linear gradient elution at a flow rate of $1 \mathrm{~mL} \mathrm{~min}{ }^{-1}$ applied for $10 \mathrm{~min}$ from $100 \%$ buffer A to $100 \%$ buffer B, and separation of proteins followed by UV detection at $278 \mathrm{~nm}$ (dotted line) and Pt elution by ICP-MS (solid line) (reproduced from ref. 38 with permission from The Royal Society of Chemistry). 
chosen to retain IgG and a CIM DEAE disk to separate unbound Pt species from those bound to HSA and Tf. By this twodimensional separation, Pt species were quantitatively eluted (column recoveries between 95 and 97\%) on the CLC monolithic column within $13 \mathrm{~min}$. At the first min, elution was isocratic with Tris-HCl- $\mathrm{NaHCO}_{3}$ buffer ( $\mathrm{pH}$ 7.4) followed by gradient elution with $1 \mathrm{~mol} \mathrm{~L}^{-1} \mathrm{NH}_{4} \mathrm{Cl}(\mathrm{pH} 7.4)$ in the next 9 min and, in the last $3 \mathrm{~min}$, finished with acetic acid ( $\mathrm{AcOH})$. During the first $10 \mathrm{~min}$ IgG was efficiently retained on the CIM protein $\mathrm{G}$ disk, enabling selective separation of unbound $\mathrm{Pt}$ from $\mathrm{Pt}$ bound to Tf and HSA on the CIM DEAE disk, using $\mathrm{NH}_{4} \mathrm{Cl}$ (pH 7.4) as the eluent. The elution with $\mathrm{AcOH}$ which followed allowed further separation of Pt bound to IgG. Separated Pt species were quantified by the post-column isotope dilution (ID)-ICP-MS. Comparison of performances of the CLC method developed with those of common procedures that involve separation of protein peaks by size-exclusion chromatography (SEC) followed by IE separation of metal-based chemotherapeutic fractions bound to serum proteins revealed that the CLC method is much faster and simpler. It was experimentally proven that it had also adequate sensitivity (LOQs for the quantification of all separated Pt species were lower than $2.4 \mathrm{ng}$ $\mathrm{Pt} \mathrm{mL}^{-1}$ ), selectivity and method repeatability (RSD $\pm 3 \%$ ), to be successfully applied in the investigation of the kinetics of the interaction of the Pt-based chemotherapeutics studied with serum proteins and the distribution of Pt species in spiked human serum. The results from such investigation indicated that cisplatin and oxaliplatin had high reactivity towards HSA but much lesser reactivity towards Tf and IgG. Around $80 \%$ of cisplatin was found to be associated with HSA, $2 \%$ with Tf and $4 \%$ with IgG. Approximately $70 \%$ of oxaliplatin was bound to HSA, $3 \%$ interacted with Tf and $11 \%$ with IgG. The proportion of unbound cisplatin and oxaliplatin was 15 and $18 \%$, respectively. The reactivity of carboplatin in spiked serum was much lower. After 48 hours of incubation, about $49 \%$ of carboplatin remained in unbound form, around $47 \%$ was bound to HSA, $2 \%$ to $\mathrm{Tf}$ and $2 \%$ to IgG. The main conclusion from the research described was that the CLC based speciation method may be reliably applied in preclinical and clinical studies of the kinetics of the interaction and distribution of different metal-based drugs with proteins in blood serum. This hypothesis was further confirmed in the study on the speciation of $\mathrm{Ru}$ in human serum. ${ }^{45}$

This study was a part of a pharmacological characterisation of a candidate $\mathrm{Ru}$ based drug. Chromatographic conditions were the same as for the separation of Pt species, protein elution was followed on-line with UV detection at $278 \mathrm{~nm}$, and the separated Ru species were quantified by post-column ID-ICPMS. The instrumental set-up enabled fast two-dimensional separation by affinity and ion-exchange modes to be carried out in a single chromatographic run. Two Ru-based chemotherapeutics were compared. A newly synthesised compound chlor$\operatorname{ido}\left(\eta^{6}-p\right.$-cymene)(nalidixicato- $\left.\kappa^{2} O, O\right) \mathrm{Ru}(\mathrm{II})(1)$ and (H2im) [trans$\left.\mathrm{Ru}(\mathrm{III}) \mathrm{Cl}_{4}(\mathrm{Him})_{2}\right](2 ; \mathrm{KP} 418)$.

The CLC procedure applied was suitable for its intended use with good sensitivity (limit of detection (LOD) $0.027 \mu \mathrm{g} \mathrm{Ru} \mathrm{mL}{ }^{-1}$ for (1)) and good repeatability (RSD $\pm 3.5 \%$ ). By applying CLCbased speciation analysis, investigation of the kinetics of interaction of positively charged and neutral complexes of Rubased drugs with serum proteins as well as their species distribution in human serum was possible (Fig. 7). Negatively charged Ru complexes, on the other hand, co-eluted with Tf and HSA and thus hindered their speciation analysis. The candidate Ru-based drug studied (1) was a neutral Ru complex that hydrolyses to a positively charged species. Therefore, it was possible to study its kinetics in human serum by the use of CLCICP-MS.

\subsection{Speciation of serum proteins based on trace metal mapping analysis}

Speciation of metals bound to proteins is one of the most challenging issues in the present metallomics research. Although a variety of hyphenated systems that combine highresolution separation techniques with highly sensitive and selective detectors have been developed, it is still difficult to identify individual metal-binding proteins due to the complexity of biological matrices. In support of these investigations Hasegawa ${ }^{40}$ developed a multiply hyphenated system for the speciation of trace elements in human serum proteins
(1)

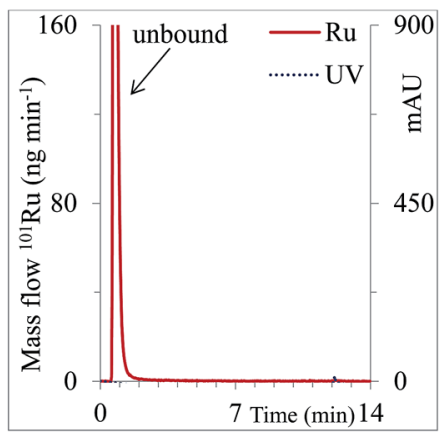

Incubated for $5 \mathrm{~min}$

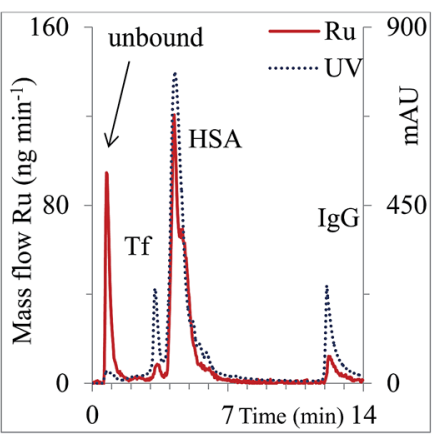

Incubated for 3 hours

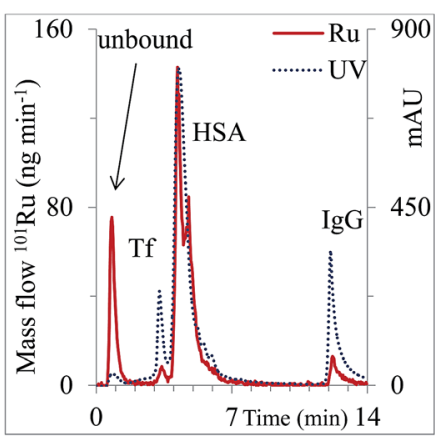

Fig. 7 Two-dimensional separation of solution of (1) $\left(1.28 \mu \mathrm{g} \mathrm{Ru} \mathrm{mL}{ }^{-1}\right)$ on a CLC monolithic column followed by ICP-MS detection and 5-times

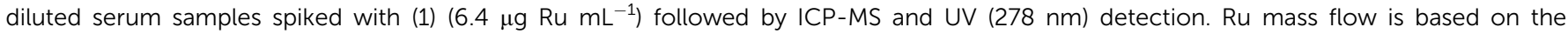
measurement of isotope ratios $\mathrm{m} / \mathrm{z} 99$ and 101 (reproduced from ref. 45 with permission from Elsevier). 
based on trace metal mapping analysis. Separation of proteins was performed by injecting $20 \mu \mathrm{L}$ of the sample onto a CIM DEAE disk using gradient elution with $1 \mathrm{M} \mathrm{CH}_{3} \mathrm{COONH}_{4}$ in 20 $\mathrm{mM}$ Tris-HCl (pH 7.4). Under optimal conditions, representative serum proteins, e.g. $\gamma$-globulin, albumin, ceruloplasmin, transferrin and $\alpha_{2}$-macroglobulin, were separated on the disk. These proteins, which were primarily assigned by UV absorption, were identified with on-line multielement detection by ICP-MS at $m / z 65$ for $\mathrm{Cu}, m / z 66$ for $\mathrm{Zn}$ and $m / z 57$ for Fe. Each successive fraction was collected and proteins were further identified off-line by MALDI-TOF-MS analysis. Characteristic chromatograms of a human sample separated on the CIM disk
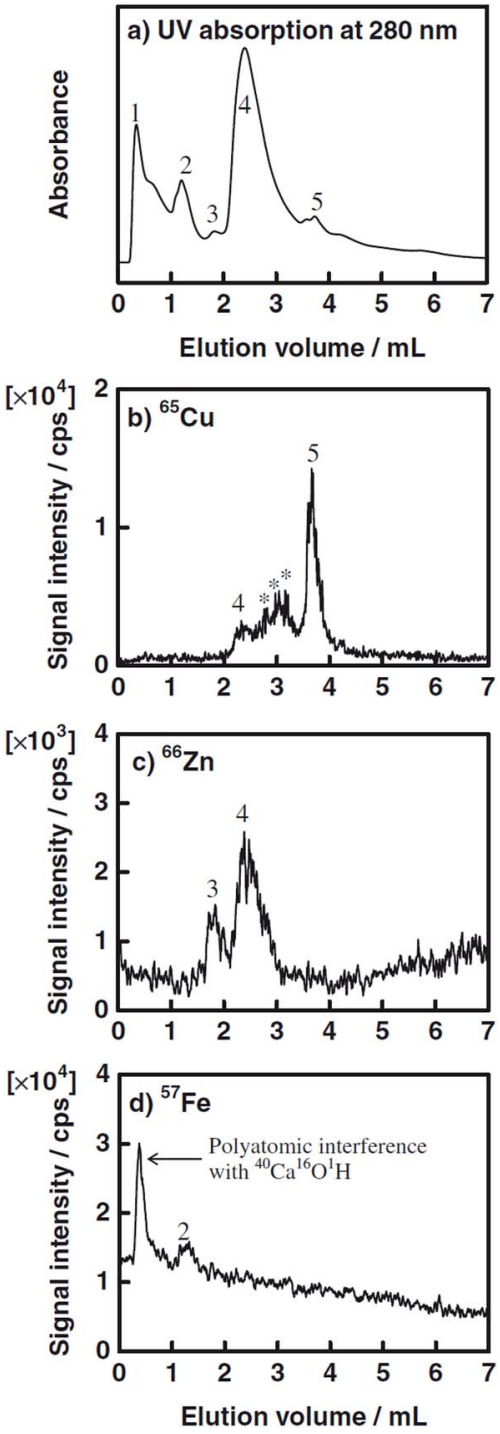

Fig. 8 Chromatograms of a human serum sample on a $3 \mathrm{~mm}$-long CIM DEAE monolithic disk column by $\mathrm{CH}_{3} \mathrm{COONH}_{4}$ gradient elution. Column size: $3 \mathrm{~mm}$ long $\times 12 \mathrm{~mm}$ i.d.; mobile phase: solvent $\mathrm{A}(20 \mathrm{mM}$ Tris- $\mathrm{HCl}$, pH 7.4), solvent $\mathrm{B}$ (buffer A containing $1 \mathrm{M} \mathrm{CH}_{3} \mathrm{COONH}_{4}$ ); linear gradient: $0-70 \% \mathrm{~B}$ in $10 \mathrm{~min}$; flow rate: $0.7 \mathrm{~mL}^{-1}$; detection: (a) UV absorption at $280 \mathrm{~nm}$, (b) ICP-MS detection at $m=z$ of 65 for $\mathrm{Cu}$, (c) $m=z$ of 66 for Zn, and (c) $m=z$ of 57 for Fe. Peaks: (1) $\gamma \mathrm{Gb}$; (2) Tf; (3) $\alpha_{2} \mathrm{Mgb}$; (4) $\mathrm{Ab}$; and (5) $\mathrm{Cp}$ (reproduced from ref. 40 with permission from The Chemical Society of Japan). followed by UV and ICP-MS detection are presented in Fig. 8. Although the chromatographic selectivity was rather poor and could be improved by careful optimization of the parameters that influence the chromatographic separation, the developed multiply hyphenated HPLC/UV/ICP-MS system equipped with a fraction collector for subsequent MALDI-TOF-MS analysis represents great potential for further identification of different proteins in biological samples.

\section{Conclusions and outlook}

Monolithic supports are widely used in chromatography as an alternative to conventional HPLC for fast separation of biomolecules. Porous monolithic stationary-phases allow efficient mass-transport at low back pressures and excellent chromatographic separations. Despite their wide use and possibilities for rapid separation of ionic species and metalbiomolecule complexes, monolithic chromatography was rarely applied in elemental speciation analysis in the field of metallomics.

Nevertheless, some successful applications in the analyses of different metal-complexes in various biological samples revealed that monolithic chromatographic supports can be employed as an efficient alternative to commonly used particle packed columns. So far, ion-pairing reversed phase chromatography using a silica based monolithic column was applied for fast and selective separation of five arsenic species in the investigation of urinary As excretion after ingestion of rice. Other applications were related to the use of methacrylatebased monolithic supports. Regarding the sample matrix and characteristics of elemental species, monolithic microcolumns, disks and larger 1 to $8 \mathrm{~mL}$ columns were applied and connected on-line with ICP-MS detection. In some studies, fractions separated on CIM supports were further subjected to mass spectrometric identification of the metal-binding complexes by ESI-MS or MALDI-TOF-MS. In investigations of Al speciation in the protein fraction of human serum, the use of a large capacity $8 \mathrm{~mL}$ CIM DEAE- 8 column and the robustness of the stationary phase to withstand rigorous cleaning with $\mathrm{NaOH}$, which consequently significantly lower the column blanks, enabled quantitative speciation of $\mathrm{Al}$ at physiological concentration levels in the serum. Speciation of essential trace elements in human serum was also reported by applying a micro-anion exchange monolithic column on a tandem HPLC system coupled on-line with an ICP-MS detector. Furthermore, CIM DEAE methacrylate-based monolithic chromatography demonstrated high potential in investigations of metallodrugbiomolecule interactions in human serum. An original 2D fully automated system was developed where the intact proteins were first separated on a SEC column. By sequential switching of the eluent from the SEC column to two parallel CIM monolithic disks coupled to ICP-MS, direct fractionation and rapid speciation analysis of cisplatin in human serum was possible. Employment of a larger CIM DEAE-1 mL column coupled to ICP-MS enables the investigation on interactions of cisplatin with serum proteins and its distribution in the serum of cancer patients who received cisplatin-based chemotherapy. The main 
advantage of the CIM DEAE-1 mL column over the use of a conventional particle packed FPLC column was that at least 150 successive serum separations could be performed before the regular cleaning of the column was necessary. CIM monolithic disks were successfully applied also in the separation of serum proteins based on trace metal mapping analysis. Fast separation at little back pressure offered possibilities to successfully use monolithic supports in $\mathrm{Zn}$ speciation analysis in human milk samples. Difficulties like preserving the integrity of $\mathrm{Zn}$ species during analysis and unwanted $\mathrm{Zn}$ interaction with various chromatographic columns or numerous buffer solutions were efficiently solved by the application of $\mathrm{Zn}$ speciation analysis, which consists of the chromatographic separation on a weak anion-exchange CIM DEAE-1 monolithic column, ICPMS detection and ES-MS-MS ligand identification. Zn-citrate was found to be the only low molecular mass $\mathrm{Zn}$ species present in human milk. The previously published data on the presence of Zn-citrate in milk perfectly agreed with those quantitatively determined by monolithic chromatography. For Ni speciation in various tea infusions it was experimentally found that low molecular Ni-quinate complexes or ionic divalent forms of $\mathrm{Ni}$ (depending on the $\mathrm{pH}$ of infusion), rather than high molecular weight Ni polyphenolic species, as presumed in the literature, were present in the samples. Assembling two different monolithic disks in single housing and hence creating a chromatographic column that enables two-dimensional separation to be carried out in a single chromatographic run was a key improvement in the development of Pt or Ru speciation analysis suitable to be implemented in pharmacokinetics studies of different Pt or Ru-based chemotherapeutics human serum samples. A CIM protein G disk was chosen to retain IgG and a CIM DEAE disk to separate unbound Pt or Ru species from those bound to HSA and Tf. All the species analysed were quantitatively eluted on the CLC monolithic column within 13 min. The examples described here clearly suggest that monolithic chromatography due to its characteristics, like the speed of analysis, has great potential to be more frequently applied in speciation of metal-containing biomolecules. Rapidness is of great importance in order to preserve chemical species of elements during the separation step and in the investigations of the kinetics of binding of metallodrugs to target molecules. With information gathered, drugs with increased effectiveness, broader spectrum of activity and reduced side effects may be designed. The advantage of the monolithic chromatography lies also in the extreme robustness of monolithic supports that sustain rigorous cleaning, which results in low column blanks. The robust monolithic supports enable also the application of a much greater number of successive separations of serum samples, before the cleaning procedure is required, than is possible by the use of conventional chromatographic columns. With good repeatability (RSD around 3\%) of consecutive chromatographic separations and comparable or even lower LODs, monolithic chromatography is an attractive alternative to particle packed columns. As a powerful separation tool, monolithic chromatography may be also introduced in the investigations of the role of metal ions in chronic neurodegenerative disorders like Alzheimer's and Parkinson's disease.
Furthermore, separation of charged low molecular mass metal complexes in a variety of biological samples would extend its applications in the field of metallomics.

\section{Acknowledgements}

This work was supported by the Ministry of Higher Education, Science and Technology of the Republic of Slovenia (Programme group P1-0143), MASSTWIN project that has received funding from the European Union's Horizon 2020 research and innovation programme under grant agreement no. 692241 and ISO-FOOD, ERA chair for isotope techniques in food quality, safety and traceability under grant agreement FP7-621329.

\section{References}

1 S. Mounicou, J. Szpunar and R. Lobinski, Chem. Soc. Rev., 2009, 38, 1119-1138.

2 P. R. Haddad, P. N. Nesterenko and W. Buchberger, J. Chromatogr. A, 2008, 1184, 456-473.

3 G. Guiochon, J. Chromatogr. A, 2007, 1168, 101-168.

4 E. G. Vlakh and T. B. Tennikova, J. Chromatogr. A, 2009, 1216, 2637-2650.

5 Monolithic Materials: Preparation, Properties and Applications, ed. F. Švec, T. B. Tennikova and Z. Deyl, Elsevier, Amsterdam, J. Chrom. Library, 2003, vol. 67, pp. 1-773.

6 O. Núñez, K. Nakanishi and N. Tanaka, J. Chromatogr. A, 2008, 1191, 231-252.

7 A. Jungbauer and R. Hahn, J. Chromatogr. A, 2008, 1184, 6279.

8 M. Barut, A. Podgornik, P. Brne and A. Štrancar, J. Sep. Sci., 2005, 28, 1876-1892.

9 R. Bandari and M. R. Buchmeiser, Analyst, 2012, 137, 32713277.

10 M. R. Buchmeiser, Polymer, 2007, 48, 2187-2198.

11 M. R. Buchmeiser, J. Chromatogr. A, 2004, 1060, 43-60.

12 A. Premstaller, H. Oberacher, W. Walcher, A. M. Timperio, L. Zolla, J.-P. Chervet, N. Cavusoglu, A. van Dorsselaer and C. G. Huber, Anal. Chem., 2001, 73, 2390-2396.

13 G. Hölzl, H. Oberacher, S. Pitsch, A. Stutz and C. G. Huber, Anal. Chem., 2005, 77, 673-680.

14 S. Lubbad, B. Mayr, C. G. Huber and M. R. Buchmeiser, J. Chromatogr. A, 2002, 959, 121-129.

15 S. H. Lubbad and M. R. Buchmeiser, J. Chromatogr. A, 2011, 1218, 2362-2367.

16 S. H. Lubbad, R. Bandari and M. R. Buchmeiser, J. Chromatogr. A, 2011, 1218, 8897-8902.

17 C. Gatschelhofer, A. Prasch, M. R. Buchmeiser, A. Zimmer, K. Wernig, M. Griesbacher, T. R. Pieber and F. M. Sinner, Anal. Chem., 2012, 84, 7415-7421.

18 M. Barut, A. Podgornik, L. Urbas, B. Gabor, P. Brne, J. Vidič, S. Plevčak and A. Štrancar, J. Sep. Sci., 2008, 31, 1867-1880.

19 N. Lendero Krajnc, F. Smrekar, J. Černe, P. Raspor, M. Modic, D. Krgović, A. Strancar and A. Podgornik, J. Sep. Sci., 2009, 32, 2682-2690.

20 F. Smrekar, M. Ciringer, A. Štrancar and A. Podgornik, J. Chromatogr. A, 2011, 1218, 2438-2444. 
21 P. Brne, A. Podgornik, K. Benčina, B. Gabor, A. Štrancar and M. Peterka, J. Chromatogr. A, 2007, 1144, 120-125.

22 E. Nesterenko, O. Yavorska, M. Macka, A. Yavorskyy and B. Paull, Anal. Methods, 2011, 3, 537-543.

23 E. G. Vlakh, G. A. Platonova, G. P. Vlasov, C. Kasper, A. Tappe, G. Kretzmer and T. B. Tennikova, J. Chromatogr. A, 2003, 992, 109-119.

24 V. Vodopivec, A. Podgornik, M. Berovič and A. Štrancar, J. Chromatogr. Sci., 2000, 38, 489-495.

25 M. Batycka, N. F. Inglis, K. Cook, A. Adam, D. Fraser-Pitt, D. G. E. Smith, L. Main, A. Lubben and B. K. Kessler, Rapid Commun. Mass Spectrom., 2006, 20, 2074-2080.

26 S. Feng, C. Pan, X. Jiang, S. Xu, H. Zhou, M. Ye and H. Zou, Proteomics, 2007, 7, 351-360.

27 J. Zhang, S.-L. Wu, J. Kim and B. L. Karger, J. Chromatogr. A, 2007, 1154, 295-307.

28 T. Čerk Petrič, P. Brne, B. Gabor, L. Govednik, M. Barut, A. Štrancar and L. Zupančič Kralj, J. Pharm. Biomed. Anal., 2007, 43, 243-249.

29 J. Ščančar and R. Milačič, Trends Anal. Chem., 2009, 28, 10481056.

30 É. Tyrrell, P. N. Nesterenko and B. Paull, J. Liq. Chromatogr. Relat. Technol., 2006, 29, 2201-2215.

31 P. Svete, R. Milačič, B. Mitrović and B. Pihlar, Analyst, 2001, 126, 1346-1354.

32 J. Ščančar and R. Milačič, Analyst, 2002, 127, 629-633.

33 G. F. Pearson, G. M. Greenway, E. I. Brima and P. I. Haris, J. Anal. At. Spectrom., 2007, 22, 361-369.

34 J. Ščančar and R. Milačič, J. Sep. Sci., 2009, 32, 2495-2503.

35 B. Kralj, J. Ščančar, I. Križaj, M. Benedik, P. Bukovec and R. Milačič, J. Anal. At. Spectrom., 2004, 19, 101-106.
36 S. Murko, R. Milačič and J. Ščančar, J. Inorg. Biochem., 2007, 101, 1234-1241.

37 S. Murko, R. Milačič, B. Kralj and J. Ščančar, Anal. Chem., 2009, 81, 4929-4936.

38 A. Martinčič, R. Milačič, M. Čemažar, G. Serša and J. Ščančar, Anal. Methods, 2012, 4, 780-790.

39 S. Hann, T. Falta, K. Boeck, M. Sulyok and G. Koellensperger, J. Anal. At. Spectrom., 2010, 25, 861-866.

40 T. Hasegawa, Y. Wakita, Y. Zhu, H. Matsuura, H. Haraguchi and T. Umemura, Bull. Chem. Soc. Jpn., 2007, 80, 503-506.

41 M. Malavolta, F. Piacenza, A. Basso, R. Giacconi, R. Costarelli, S. Pierpaoli and E. Mocchegiani, Anal. Biochem., 2012, 421, 16-25.

42 R. Milačič, D. Ajlec, T. Zuliani, D. Žigon and J. Ščančar, Talanta, 2012, 101, 203-210.

43 J. Ščančar, T. Zuliani, D. Žigon and R. Milačič, Anal. Bioanal. Chem., 2013, 405, 2041-2051.

44 A. Martinčič, M. Cemazar, G. Sersa, V. Kovač, R. Milačič and J. Ščančar, Talanta, 2013, 116, 141-148.

45 A. Martinčič, R. Milačič, J. Vidmar, I. Turel, B. K. Keppler and J. Ščančar, J. Chromatogr. A, 2014, 1371, 168-176.

46 E. Schmeisser, W. Goessler, N. Kienzl and K. A. Francesconi, Analyst, 2005, 130, 948-955.

47 J. Vidič, A. Podgornik, J. Jančar, V. Smrekar, B. Košir, N. Lendero Krajnc, K. Čuček, M. Krajnc and A. Štrancar, J. Chromatogr. A, 2007, 1144, 63-71.

48 A. Sanz-Medel, A. B. Soldado Cabezuelo, R. Milačič and T. Bantan Polak, Coord. Chem. Rev., 2002, 228, 373-383.

49 A. Belen Soldado Cabezuelo, M. Montes Bayón, E. Blanco González, J. I. Garcia Alonso and A. Sanz-Medel, Analyst, 1998, 123, 865-869. 